\title{
Constipation Misperception Is Associated With Gender, Marital Status, Treatment Utilization and Constipation Symptoms Experienced
}

\author{
Tae Hee Lee, ${ }^{1}$ Suck Chei Choi, ${ }^{2 *}$ Moo In Park, ${ }^{3}$ Kyung Sik Park, ${ }^{4}$ Jeong Eun Shin, ${ }^{5}$ Seong-Eun Kim, ${ }^{6}$ Kee Wook Jung, ${ }^{7}$ \\ Hoon Sup Koo, ${ }^{8}$ Wan Jung Kim, ${ }^{9}$ Young Kwan Cho, ${ }^{10}$ Yeon Soo Kim ${ }^{11}$ and Ji Sung Lee ${ }^{12}$; Constipation Group of the Korean \\ Society of Neurogastroenterology and Motility

\begin{abstract}
${ }^{1}$ Institute for Digestive Research, Digestive Disease Center, Soonchunhyang University Hospital, Seoul, Korea; ${ }^{2}$ Department of Internal Medicine and Digestive Disease Research Institute, Wonkwang University College of Medicine, Iksan, Korea; ${ }^{3}$ Department of Internal Medicine, Kosin University College of Medicine, Busan, Korea; ${ }^{4}$ Department of Internal Medicine, Keimyung University College of Medicine, Daegu, Korea; ${ }^{5}$ Division of Gastroenterology, Department of Internal Medicine, Dankook University Hospital, Dankook University College of Medicine, Cheonan, Chungcheongnam-do, Korea; 'Department of Internal Medicine, Ewha Mokdong Hospital, Ewha Womans University School of Medicine, Seoul, Korea: ${ }^{7}$ Asan Digestive Disease Research Institute, Department of Gastroenterology, Asan Medical Center, University of Ulsan College of Medicine, Seoul, Korea; ${ }^{8}$ Department of Internal Medicine, Konyang University College of Medicine, Daejeon, Korea; ${ }^{9}$ Department of Internal Medicine, Soonchunhyan University Gumi Hospital, Gumi, Korea; ${ }^{10}$ Department of Internal Medicine, Eulji General Hospital, Eulji University College of Medicine, Seoul, Korea; ${ }^{11}$ Department of Internal Medicine, Hallym University College of Medicine, Chuncheon Sacred Heart Hospital, Gangwon-do, Korea; and ${ }^{12}$ Biostatistical Consulting Unit, Soonchunhyang University Medical Center, Seoul, Korea
\end{abstract}

\begin{abstract}
Background/Aims
It is essential that clinicians have an understanding of patients' perceptions of constipation as well as constipation misperception (CM), which can be defined as failure to recognize the six constipation symptoms (infrequency, straining, hard stool, incomplete evacuation, anorectal obstruction or manual maneuver). The aims of our study were to identify the prevalence of CM and its association with demographics and clinical features.
\end{abstract}

\section{Methods}

This nationwide survey included 625 self-reported constipated subjects (431 females; mean age, 41.2 years) among random participants in the National Health Screening Program. The prevalence of CM for each constipation symptom was estimated, and the participants were classified into nil (0), low (1-2), mid (3-4) and high (5-6) level CM subgroups according to the number of misperceived symptoms.

Results

The highest rate of CM was observed for manual maneuver (48.3\%), followed by anorectal obstruction (38.4\%), stool infrequency (34.6\%), incomplete evacuation (32.2\%), hard stool (27.2\%) and straining (25.4\%). Among the nil $(n=153)$, low

Received: February 9, 2014 Revised: April 1, 2014 Accepted: April 1, 2014

(c) This is an Open Access article distributed under the terms of the Creative Commons Attribution Non-Commercial License (http://creativecommons. org/licenses/by-nc/3.0) which permits unrestricted non-commercial use, distribution, and reproduction in any medium, provided the original work is properly cited.

*Correspondence: Suck Chei Choi, PhD, MD

Department of Internal Medicine and Digestive Disease Research Institute, Wonkwang University College of Medicine, 460 Iksan-daero, Iksan 570-974, Korea

Tel: +82-63-859-2563, Fax: +82-63-855-2025, E-mail: medcsc@wmc.wonkwang.ac.kr

Financial support: None.

Conflicts of interest: None.

Author contributions: Tae Hee Lee and Suck Chei Choi contributed equally to this work. Tae Hee Lee, Suck Chei Choi, Moo In Park, Kyung Sik Park, Jeong Eun Shin, Seong-Eun Kim, Hoon Sup Koo, Wan Jung Kim and Young Kwan Cho collected data and drafted the paper; Kee Wook Jung edited the paper; Yeon Soo Kim reviewed data analysis; Ji Sung Lee performed statistical analyses.

ORCID: Tae Hee Lee, http://orcid.org/0000-0003-3049-8252. 
( $n=242)$, mid $(n=144)$ and high level $(n=86)$ subgroups, there were significant differences in the proportions of males $(18.3 \%, 34.3 \%, 39.6 \%$ and $30.2 \% ; P=0.001$, respectively), never-married status $(25.7 \%, 38.2 \%, 36.8 \%$ and $45.9 \% ; P=$ 0.030 , respectively) and those who did not receive treatment for constipation $(41.8 \%, 47.5 \%, 58.3 \%$ and $66.3 \% ; P<0.001$, respectively). There was a significant linear trend of increasing degree of $\mathrm{CM}$ with decreasing symptoms experienced $(P<$ $0.001)$.

\section{Conclusions}

$\mathrm{CM}$ is significantly associated with gender, marital status, treatment utilization and the range of constipation symptoms experienced.

\section{(J Neurogastroenterol Motil 2014;20:379-387)}

Key Words

Constipation; Health surveys; Perception

\section{Introduction}

Constipation is a major public health issue because of its high prevalence, economic cost, and adverse effects on quality of life and health status. ${ }^{1}$ It is not a specific disease but a general term that describes a wide range of symptoms associated with straining, hard stools, incomplete evacuation, anorectal obstruction, manual maneuvers or infrequent stools. ${ }^{2}$ Additionally, individuals experience symptoms of constipation differently. ${ }^{3,4}$ Although physicians focus on the infrequency of stools, patients are more concerned with ease of passage and consistency of stools rather than frequency. ${ }^{5-8}$ Their perception of constipation might contribute to some of the variability in reported constipation symptoms. For example, some individuals with $<3$ bowel movements per week do not consider themselves constipated, while others with daily bowel movements report constipation. The definition of constipation has little correlation reported between physicians and patients. ${ }^{9,10}$ While a detailed evaluation of reported symptoms in patients with self-reported constipation has been reported, minimal data are available on the perceptions of constipated patients. ${ }^{3,4,9}$

Some patients do not think that constipation symptoms could be anything serious or that they require evaluation by a physician. Furthermore, some patients believe that the symptoms are simply a part of the bowel experience rather than what physicians define as constipation. These observations suggest that some patients lack knowledge of the definition of constipation. They are not educated, and physicians do not have the time to educate them. Constipated patients could develop a new understanding of constipation through the Internet, but obviously, some websites contain misleading information.

For this study, constipation misperception (CM) among constipated individuals was defined as the failure to recognize that stool infrequency, straining, hard stool, incomplete evacuation, anorectal obstruction or manual maneuver are symptoms of constipation. CM may be an important barrier to the effective treatment and prevention of constipation, because a key to optimizing care for patients with constipation is to recognize its presence. In this context, it is essential that clinicians have a better understanding of CM. To the best of our knowledge, previous studies have not described either the prevalence of CM or its association with demographics, symptoms experienced, or types of treatment utilization.

\section{Materials and Methods}

\section{Subjects}

This survey population consisted of random contributors who participated between January 10 and June 30, 2012 in the National Health Screening Program (NHSP), which is available to most Koreans at least every other year. ${ }^{11}$ Recruits were eligible to participate in this study if they were $\geq 20$ years of age, considered themselves constipated, and completed $>80 \%$ of the items in our questionnaire. Subjects were excluded from the study if they were illiterate, blind, unwilling to participate in the study, or if they had received a physician's diagnosis of irritable bowel syndrome (IBS) or secondary constipation. The participants in the study did not receive any reimbursement. The principal investigator (SCC) covered the material costs. All participants provided written informed consent prior to the study. The Institutional Review Boards of Soonchunhyang University Seoul Hospital, South Korea approved the study protocol (SCH Seoul IRB-2012-009). 
Table 1. Demographics and Clinical Features of Respondents

\begin{tabular}{|c|c|c|}
\hline \multicolumn{3}{|l|}{ Sex } \\
\hline & Male & $194(31.0)$ \\
\hline & Female & $431(69.0)$ \\
\hline \multicolumn{3}{|l|}{ Age (yr) } \\
\hline & Mean (SD) & $41.2(15.5)$ \\
\hline & Range & $20-89$ \\
\hline Body mass index & Mean (SD) & $22.3(3.0)$ \\
\hline \multicolumn{3}{|l|}{ Alcohol } \\
\hline & Yes & $148(23.9)$ \\
\hline & No & $472(76.1)$ \\
\hline \multicolumn{3}{|l|}{ Smoking } \\
\hline & Yes & $321(51.7)$ \\
\hline & No & $300(48.3)$ \\
\hline \multicolumn{3}{|l|}{ Marital status } \\
\hline & Married & $354(56.9)$ \\
\hline & Widowed/divorced/separated & $45(7.2)$ \\
\hline & Never married & $223(35.9)$ \\
\hline \multicolumn{3}{|l|}{ Education level } \\
\hline & Low & $303(48.6)$ \\
\hline & High & $320(51.4)$ \\
\hline \multicolumn{3}{|l|}{ Regular exercise } \\
\hline & Yes & $99(26.5)$ \\
\hline & No & $275(73.5)$ \\
\hline \multicolumn{3}{|l|}{ Occupation } \\
\hline & White collar & $288(56.0)$ \\
\hline & Blue collar & $80(15.5)$ \\
\hline & None & $147(28.5)$ \\
\hline \multicolumn{3}{|l|}{ Co-morbidity } \\
\hline & Yes & $175(28.8)$ \\
\hline & No & $432(71.2)$ \\
\hline \multicolumn{3}{|l|}{ Medications } \\
\hline & Yes & $162(26.8)$ \\
\hline & No & $442(73.2)$ \\
\hline \multicolumn{3}{|c|}{ Symptoms experienced } \\
\hline & Defecation $<3$ times/wk & $363(58.9)$ \\
\hline & Hard stool $\geq 25 \%$ & $359(58.9)$ \\
\hline & Straining $\geq 25 \%$ & $400(64.6)$ \\
\hline & Sensation of incomplete evacuation $\geq 25 \%$ & $392(64.2)$ \\
\hline & Sensation of anorectal obstruction $\geq 25 \%$ & $243(39.5)$ \\
\hline & Manual maneuvers to facilitate $\geq 25 \%$ & $91(14.8)$ \\
\hline \multicolumn{3}{|c|}{ Number of symptoms experienced } \\
\hline & Rome III-0/6 & $30(4.8)$ \\
\hline & Rome III-1/6 & $110(17.6)$ \\
\hline & Rome III-2/6 & $116(18.6)$ \\
\hline & Rome III-3/6 & $133(21.3)$ \\
\hline & Rome III-4/6 & $123(19.7)$ \\
\hline & Rome III-5/6 & $63(10.1)$ \\
\hline & Rome III-6/6 & $50(8.0)$ \\
\hline \multicolumn{3}{|c|}{ Treatment received within the previous 6 months } \\
\hline & No treatment & $320(51.2)$ \\
\hline & Physician visit & $98(15.7)$ \\
\hline & Self treatment & $207(33.1)$ \\
\hline
\end{tabular}

Data were presented as number $(\%)$. 


\section{Questionnaire}

The main questionnaire comprised three parts. The first part was designed to elicit demographic data (age, sex, body mass index, alcohol use, smoking history, marital status, educational level, regular exercise and occupation). Marital status was categorized as married, widowed/divorced/separated, or never married. Educational level was dichotomized based on completed education: low (high school graduate or less) and high (college or more) levels. Occupation was classified as white collar, blue collar or none. White collar refers to a person who performs professional, managerial or administrative work, in contrast to a blue collar worker, whose job requires manual labor.

The second part addressed clinical data including co-morbidity, use of constipation treatment within the past 6 months, and 6 symptoms of Rome III functional constipation. The type of treatment utilization was divided into no treatment (no constipation relief therapy), physician visit (prescription medication or biofeedback therapy), and self-treatment (trial of over-thecounter medication, Oriental medication or a folk remedy for the relief of constipation).

In the final portion of the questionnaire, participants were asked to rate their opinions on a series of statements regarding the definition of constipation on a 5-point Likert scale (strongly agree, agree, undecided, disagree and strongly disagree). These statements included 6 items: (1) having fewer than three defecations per week (infrequency), (2) applying too much effort to pass stool (straining), (3) having hard stool (hard stool), (4) sensation of anorectal obstruction or blockage (anorectal obstruction), (5) sensation of incomplete emptying of the bowel (incomplete evacuation) and (6) using fingers to help empty your bowel (manual maneuver). Data collection relied on paper-and-pencil administration by interviewers or self-administration by respondents.

\section{Data Analysis}

For each of the six statements regarding the definition of constipation, a negative response ("strongly disagree," "disagree" and "undecided") was defined as CM. Based on the number of $\mathrm{CM}$ cases, the subjects were classified into nil (0), low (1-2), mid (3-4) and high (5-6) CM groups.

\section{Statistical Methods}

Summary statistics such as mean values, standard deviations for continuous variables, and counts and percentages for categorical variables and confidence intervals, when appropriate, were calculated. The prevalence of CM was estimated for constipated Korean adult participants. Characteristics of the nil, low, mid, and high level groups were compared using the Chi-square test for categorical variables and analysis of variance (ANOVA) for continuous variables as appropriate. All analyses were performed using the Statistical Package for the Social Sciences (SPSS, version 12.0, Chicago, IL, USA). $P$-values $<0.05$ were considered indicative of statistical significance.

\section{Results}

The 835 subjects were random participants in the NHSP who considered themselves constipated. Of these respondents, 625 (74.9\%) were eligible. Table 1 shows the demographic and clinical findings of all respondents. Their mean age was 41.2 (range, 20-89) years, and 431 (69.0\%) were females. The most commonly experienced symptom was straining (64.6\%), followed by incomplete evacuation (64.2\%), infrequency (58.9\%), hard stool $(58.9 \%)$, anorectal obstruction $(39.5 \%)$ and manual maneuver $(14.8 \%)$. Overall, $62.3 \%$ reported a $\geq 6$-month history of constipation symptoms, $51.2 \%$ did not receive constipation relief therapy, $15.7 \%$ received prescription medication (including biofeedback therapy) and $33.1 \%$ were self-treated with over-the-counter medications, Oriental medications, or folk remedies.

Figure 1 shows variable ranges of perception of constipation in our respondents. For each of the 6 statements regarding the definition of constipation, a positive response ("strongly agree" or "agree") was defined as constipation perception. Based on the

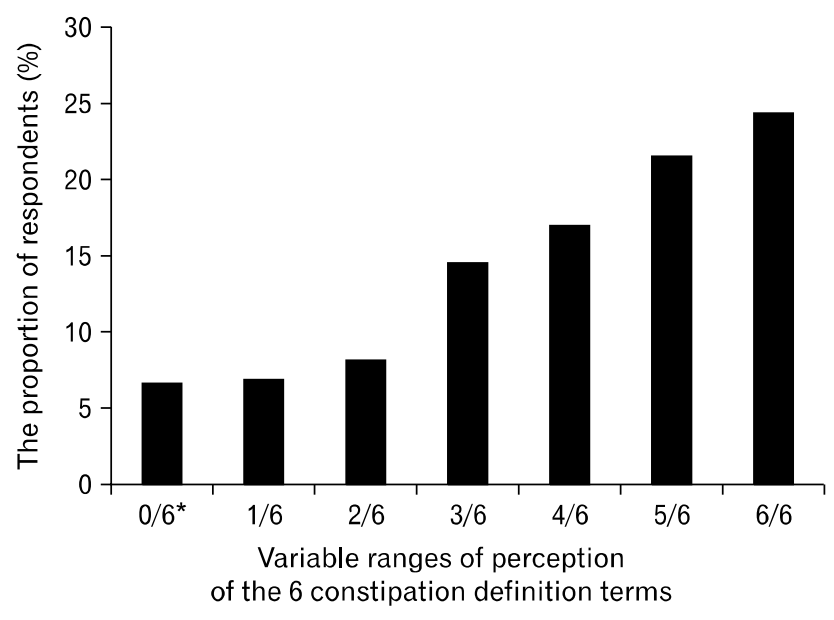

Figure 1. Proportion of respondents based on the number with constipation perception for each of the 6 constipation symptoms. *Those who did not perceive any of the 6 symptoms as constipation. 
number of constipation perception cases, the $0 / 6$ (those who did not perceive any of the 6 symptoms as constipation), 1/6, 2/6, 3/6, $4 / 6,5 / 6$ and 6/6 subgroups accounted for $6.7 \%, 7.0 \%, 8.3 \%$, $14.7 \%, 17.1 \%, 21.6 \%$ and $24.5 \%$, respectively.

\section{The Prevalence of Constipation Misperception}

Figure 2 shows the proportion of participants who had CM for each of the constipation definition terms. The highest rate of CM was observed for manual maneuver $(302 / 625,48.3 \%)$, followed by anorectal obstruction $(240 / 625,38.4 \%)$, stool infrequency $(216 / 625,34.6 \%)$, incomplete evacuation (201/625, $32.2 \%)$, hard stool $(170 / 625,27.2 \%)$ and straining $(159 / 625$, $25.4 \%)$.

According to the number of $\mathrm{CMs}$, the proportions of $\mathrm{CM}-0 / 6$ (those who perceived all 6 symptoms as constipation), CM-1/6, CM-2/6, CM-3/6, CM-4/6, CM-5/6 and CM-6/6 were $24.5 \%$, $21.6 \%, 17.1 \%, 14.7 \%, 8.3 \%, 7.0 \%$ and $6.7 \%$, respectively.

\section{Comparison of Constipation Misperceptions Based on Each Symptom Experienced}

Table 2 shows a comparison of CMs for the relevant symptoms based on the presence of each symptom experienced. Those who did not experience defecation $<3$ times/week had a significantly higher rate of CM for infrequency, compared with those who did experience it ( $54.3 \%$ vs. $23 \%, P<0.001)$. Those who did not report hard stool $\geq 25 \%$ had a significantly higher rate of CM for hard stool, compared with those who did report it (43.4\% vs. $16.6 \%, P<0.001)$. Those who did not experience straining $\geq 25 \%$ had a significantly higher rate of $\mathrm{CM}$ for straining, compared with those who did experience it $(44.7 \%$ vs. $15.6 \%, P<0.001)$. Those who did not report sensation of incomplete evacuation $\geq 25 \%$ had a significantly higher rate of
$\mathrm{CM}$ for incomplete evacuation, compared to those who did report it ( $50.5 \%$ vs. $23.8 \%, P<0.001)$. Those who did not experience the sensation of anorectal obstruction $\geq 25 \%$ had a significantly higher rate of $\mathrm{CM}$ for anorectal obstruction, compared with those who did experience it (51\% vs. $23.3 \%, P<0.001)$. Those who did not report manual maneuvers to facilitate defecation $\geq 25 \%$ had a significantly higher rate of $\mathrm{CM}$ for manual support, compared with those who did report them (53.9\% vs. $28.9 \%, P<0.001)$.

\section{Characteristics of Participants According to the Level of Constipation Misperception}

The proportions of participants in the nil, low, mid and high level subgroups were $24.5 \%, 38.6 \%, 23.1 \%$ and $13.8 \%$, respectively. There were significant differences in gender, marital sta-

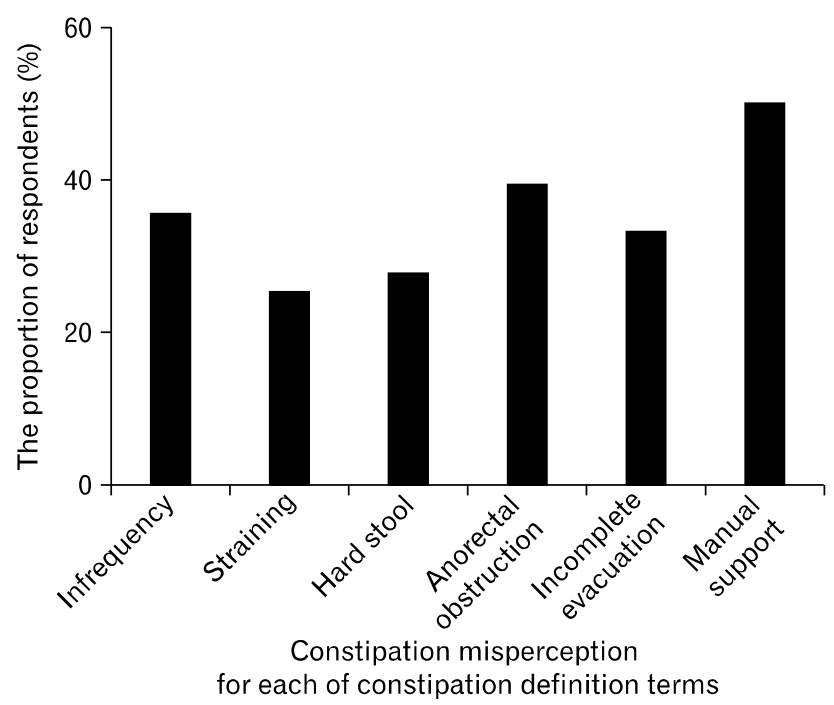

Figure 2. The rate of constipation misperception for 6 constipation symptoms.

Table 2. Comparison of Constipation Misperception for the Relevant Symptoms Based on Each Symptom Experienced

\begin{tabular}{|c|c|c|c|c|c|c|c|c|c|c|c|c|}
\hline \multirow[t]{2}{*}{$\begin{array}{l}\text { Symptoms } \\
\text { experienced }\end{array}$} & \multicolumn{2}{|c|}{$\begin{array}{l}\text { Defecation } \\
<3 \text { times/wk }\end{array}$} & \multicolumn{2}{|c|}{$\begin{array}{c}\text { Hard stool } \\
\geq 25 \%\end{array}$} & \multicolumn{2}{|c|}{$\begin{array}{l}\text { Straining } \\
\geq 25 \%\end{array}$} & \multicolumn{2}{|c|}{$\begin{array}{l}\text { Sensation of } \\
\text { incomplete } \\
\text { evacuation } \\
\geq 25 \%\end{array}$} & \multicolumn{2}{|c|}{$\begin{array}{l}\text { Sensation of } \\
\text { anorectal } \\
\text { obstruction } \\
\geq 25 \%\end{array}$} & \multicolumn{2}{|c|}{$\begin{array}{l}\text { Manual } \\
\text { maneuvers to } \\
\text { facilitate } \\
\geq 25 \%\end{array}$} \\
\hline & No & Yes & No & Yes & No & Yes & No & Yes & No & Yes & No & Yes \\
\hline $\begin{array}{l}\text { Constipation } \\
\text { misperception }(\%)^{\mathrm{a}}\end{array}$ & $\begin{array}{c}134 \\
(54.3)\end{array}$ & $\begin{array}{c}82 \\
(23.0)\end{array}$ & $\begin{array}{c}111 \\
(43.4)\end{array}$ & $\begin{array}{c}59 \\
(16.6)\end{array}$ & $\begin{array}{c}97 \\
(44.7)\end{array}$ & $\begin{array}{c}62 \\
(15.6)\end{array}$ & $\begin{array}{c}109 \\
(50.5)\end{array}$ & $\begin{array}{c}92 \\
(23.8)\end{array}$ & $\begin{array}{c}184 \\
(51.0)\end{array}$ & $\begin{array}{c}56 \\
(23.3)\end{array}$ & $\begin{array}{c}276 \\
(53.9)\end{array}$ & $\begin{array}{c}26 \\
(28.9)\end{array}$ \\
\hline$P$-value & \multicolumn{2}{|c|}{$<0.001$} & \multicolumn{2}{|c|}{$<0.001$} & \multicolumn{2}{|c|}{$<0.001$} & \multicolumn{2}{|c|}{$<0.001$} & \multicolumn{2}{|c|}{$<0.001$} & \multicolumn{2}{|c|}{$<0.001$} \\
\hline
\end{tabular}

${ }^{\text {a } C o n s t i p a t i o n ~ m i s p e r c e p t i o n ~ i n d i c a t e s ~ f a i l u r e ~ t o ~ r e c o g n i z e ~ t h e ~ r e l e v a n t ~ s y m p t o m ~ f o r ~ e a c h ~ s y m p t o m ~ e x p e r i e n c e d . ~}$

$P$-value by Chi-square test. 
Table 3. Demographics and Clinical Features According to Level of Constipation Misperception

\begin{tabular}{|c|c|c|c|c|c|}
\hline & $\begin{array}{l}\text { Nil } \\
(0 / 6)\end{array}$ & $\begin{array}{l}\text { Low-level } \\
(1-2 / 6)\end{array}$ & $\begin{array}{c}\text { Mid-level } \\
(3-4 / 6)\end{array}$ & $\begin{array}{c}\text { High-level } \\
(5-6 / 6)\end{array}$ & $P$-value \\
\hline Mean age (yr) & $42.5 \pm 14.6$ & $41.4 \pm 15.6$ & $40.1 \pm 15.6$ & $39.9 \pm 16.7$ & 0.517 \\
\hline Sex & & & & & 0.001 \\
\hline Male & $28(18.3)$ & $83(34.3)$ & $57(39.6)$ & $26(30.2)$ & \\
\hline Female & $125(81.7)$ & $159(65.7)$ & $87(60.4)$ & $60(69.8)$ & \\
\hline BMI $\left(\mathrm{kg} / \mathrm{m}^{2}\right)$ & $22.4 \pm 3.3$ & $22.1 \pm 3.0$ & $22.4 \pm 3.2$ & $22.1 \pm 3.0$ & 0.659 \\
\hline Smoking & & & & & 0.587 \\
\hline Yes & $76(50)$ & $123(50.8)$ & $81(56.6)$ & $41(48.8)$ & \\
\hline No & $76(50)$ & $119(49.2)$ & $62(43.4)$ & $43(51.2)$ & \\
\hline Alcohol & & & & & 0.553 \\
\hline Yes & $32(21.1)$ & $55(22.7)$ & $39(27.5)$ & $22(26.2)$ & \\
\hline No & $120(78.9)$ & $187(77.3)$ & $103(72.5)$ & $62(73.8)$ & \\
\hline Marital status & & & & & 0.030 \\
\hline Married & $101(66.4)$ & $131(54.4)$ & $84(58.3)$ & $38(44.7)$ & \\
\hline Widowed/divorced/separated & $12(7.9)$ & $18(7.5)$ & $7(4.9)$ & $8(9.4)$ & \\
\hline Never married & $39(25.7)$ & $92(38.2)$ & $53(36.8)$ & $39(45.9)$ & \\
\hline Education level & & & & & 0.067 \\
\hline Low & $67(43.8)$ & $109(45.2)$ & $82(56.9)$ & $45(52.9)$ & \\
\hline High & $86(56.2)$ & $132(54.8)$ & $62(43.1)$ & $40(47.1)$ & \\
\hline Regular exercise & & & & & 0.925 \\
\hline Yes & $26(25.5)$ & $35(25.2)$ & $25(28.7)$ & $13(28.3)$ & \\
\hline No & $76(74.5)$ & $104(74.8)$ & $62(71.3)$ & $33(71.7)$ & \\
\hline Occupation & & & & & 0.059 \\
\hline White collar & $79(64.2)$ & $117(56.8)$ & $58(49.6)$ & $34(49.3)$ & \\
\hline Blue collar & $22(17.9)$ & $25(12.1)$ & $20(17.1)$ & $13(18.8)$ & \\
\hline None & $22(17.9)$ & $64(31.1)$ & $39(33.3)$ & $22(31.9)$ & \\
\hline Co-morbidity & & & & & 0.873 \\
\hline Yes & $41(27.3)$ & $72(30.6)$ & $40(28.6)$ & $22(26.8)$ & \\
\hline No & $109(72.7)$ & $163(69.4)$ & $100(71.4)$ & $60(73.2)$ & \\
\hline Medications & & & & & 0.942 \\
\hline Yes & $41(27.2)$ & $65(27.9)$ & $36(25.9)$ & $20(24.7)$ & \\
\hline No & $110(72.8)$ & $168(72.1)$ & $103(74.1)$ & $61(75.3)$ & \\
\hline Treatment utilization & & & & & $<0.001$ \\
\hline No treatment & $64(41.8)$ & $115(47.5)$ & $84(58.3)$ & $57(66.3)$ & \\
\hline Physician visit & $38(24.8)$ & $32(13.2)$ & $20(13.9)$ & $8(9.3)$ & \\
\hline Self-treatment & $51(33.3)$ & $95(39.3)$ & $40(27.8)$ & $21(24.4)$ & \\
\hline Symptoms experienced & & & & & $<0.001$ \\
\hline Rome III- 0-2/6 & $48(31.4)$ & $70(28.9)$ & $74(51.4)$ & $64(74.4)$ & \\
\hline Rome III- 3-6/6 & $105(68.6)$ & $172(71.1)$ & $70(48.6)$ & $22(25.6)$ & \\
\hline
\end{tabular}

BMI, body mass index.

Values represent the number of patients $(\%)$ or means $\pm \mathrm{SD}$, unless otherwise indicated. $P$-values were calculated by ANOVA, Pearson's Chi-square test or linear trend test, as appropriate.

tus, treatment utilization, and the range of symptoms experienced among the 4 subgroups (Table 3). A significant difference was observed in the proportion of males among the 4 subgroups (18.3\%, 34.3\%, 39.6\% and 30.2\%; $P=0.001$, respectively). The proportion of never married participants was increased sig- nificantly from the nil (25.7\%) to high (45.9\%) subgroups ( $P=$ $0.030)$. There was a significant difference in the proportion of "no treatment" responses among the subgroups $(41.8 \%, 47.5 \%$, $58.3 \%$ and $66.3 \% ; P<0.001$, respectively). The proportions of nil, low, mid and high level subgroups among those who experi- 
enced fewer than three constipated symptoms (Rome III-0-2/6) were $31.4 \%, 28.9 \%, 51.4 \%$ and $74.4 \%$, respectively. In contrast, the proportions of nil, low, mid and high level subgroups among those who had more than 3 constipated symptoms were $68.6 \%$, $71.1 \%, 48.6 \%$ and $25.6 \%$, respectively. There was a significant linear trend of increasing $\mathrm{CM}$ level with decreasing symptoms experienced $(P<0.001)$.

\section{Discussion}

This nationwide South Korean survey is the first study to show how adults with self-reported constipation differentially perceive constipation. The data provide information relevant to $\mathrm{CM}$ as a unique challenge and novel potential target in the constipation treatment paradigm. Previous studies have reported on the different constipation symptoms experienced among individuals as well as the different perceptions between physicians and patients. However, no previous study has described the demographics and clinical features associated with CM.

Taking into account the previous studies, ${ }^{5-8}$ it is not surprising that the rates of $\mathrm{CM}$ on subjective items (i.e., straining and hard stools) were lower compared with those of the objective item (infrequent stool). It should be noted that approximately $37 \%$ of patients with self-reported constipation had greater than mid-level CM. This knowledge deficit may be compounded by less discussion about constipation during physician appointments, which then may impede effective treatment and prevention for constipated patients with CM. On the other hand, a condition that the physician does not define as constipation may be mistaken for constipation by patients with self-reported constipation. In this situation, inadequate counseling by physicians may contribute to inappropriate health interventions. Therefore, $\mathrm{CM}$ is not only an interesting phenomenon but also has important public health implications.

The majority of studies report a higher prevalence of constipation in females than in males, with a median female-to-male ratio of 2.2. ${ }^{12}$ Interestingly, higher ratios were observed in studies that relied on self-reported constipation (mean $=2.65$ ) rather than the Rome criteria (mean $=1.5$ ). These findings suggest that there might be gender-specific differences in the perceptions about constipation. Contradictory information exists about gender-based differences in constipation symptoms experienced. ${ }^{13-16}$ In the present study, the symptoms experienced were comparable between males and females (data not shown), but the CM level was significantly higher in male participants. This result explains why females have a higher prevalence of constipation than males, particularly in epidemiologic studies that rely on self-reported constipation.

To our knowledge, marital status does not influence the development of chronic constipation. ${ }^{17}$ In our study, marital status significantly affected the level of CM. Married individuals may have better recognition of constipation symptoms because we surmised that their potentially constipated spouses might inform or counsel these individuals about constipation.

In our study, we found a significant linear trend between an increasing level of $\mathrm{CM}$ and a decline in the symptoms experienceed. It is not surprising that symptoms experienced impact the perception of constipation. With respect to each of the 6 constipation symptoms, there was a significantly higher rate of $\mathrm{CM}$ in those who did not experience each of them. However, there was also a mismatch between their perception and experience for each constipation symptom. For example, $16.6 \%$ of those who experienced hard stools did not recognize hard stools as a constipation symptom. They might perceive hard stools as just mild discomfort rather than a more bothersome constipation symptom. In fact, the most severe symptom differed among individuals with constipation. Therefore, this mismatch might suggest that severity of constipation symptoms affects their perception.

Interestingly, $4.8 \%(30 / 625)$ of participants felt that they had constipation yet did not complain of any constipation symptoms. Furthermore, $80 \%$ of them failed to recognize any of the six constipation symptoms as constipation. These patients' "constipation" may be the result of their different perceptions or expectations of what it is to have normal bowel function. For example, individuals might perceive that if they do not have normal bowel function, they will feel bloating. If they experience bloating, they consider themselves constipated despite the absence of the symptoms that physicians typically use to define constipation (straining, hard stools, infrequent stools and incomplete evacuation etc.). A preliminary study reported that bloating was the most common and bothersome complaint in Chinese and Indian patients. ${ }^{18}$ Furthermore, several medical conditions (e.g., anal fissure, IBS and hemorrhoids) commonly occur in these patients. In this context, some patients sometimes use the term "constipation" to describe painful defecation, which is usually the consequence of anal fissure disease. These reports indicate that the variety of presenting symptoms associated with chronic constipation may pose a significant challenge for diagnosis if the clinician does not recognize the connection among the complaints.

Although constipation is a common problem, only a small 
portion of constipated patients seeks medical care. When constipated patients were asked their reasons for not seeking health care, $36 \%$ said that they did not consider their condition to be severe, while $22 \%$ did not consider themselves constipated. ${ }^{3}$ Our study showed that the CM level is higher in those who did not receive any treatment for constipation relief. These findings indicate that $\mathrm{CM}$ is an important factor affecting treatment behavior. Therefore, physicians must not only identify and counsel constipated patients with CM in the clinical setting but also partner with public health and community advocates to develop treatment programs that reach these individuals in their own communities.

There were 2 limitations in the present study. First, constipated individuals with IBS or secondary causes may have been included in the present study, even though we excluded participants with a physician's diagnosis of IBS or secondary constipation. However, observational studies and expert opinions indicate that functional constipation frequently overlaps with IBS with functional constipation. ${ }^{19}$ In some patients, it may be difficult, if not impossible, to differentiate functional constipation and IBS accurately and reliably. Second, our study did not reveal whether differences in perception exist between constipated patients with or without self-reported constipation and non-constipated subjects. However, it is important to recognize the perception of constipation in self-reporting patients, because individuals who do not identify themselves as constipated are unlikely to experience a social and economic burden due to the condition.

In our study, the study population consited of individuals who participated in the NHSP, which is available to most Koreans at least every alternate year. Most Korean health care practitioners are highly likely to agree that they are representative of the Korean population. Given our study population, our findings are unlikely to limit the genealizability of Korean patient's views on constipation. However, these findings might not be consistent across all Asian populations because of racial and sociodemographic differences.

In conclusion, adults with self-reported constipation perceive constipation differently. A large portion has a varying degree of $\mathrm{CM}$, which is significantly associated with gender, marital status, treatment behavior and the range of symptoms experienced. This study enhances our understanding of the epidemiology of constipation. Furthermore, our findings may be useful for patient education in clinical practice or for developing programs to increase public awareness about constipation. Acknowledging and in- corporating the findings into clinical practice will increase the quality of management for constipated patients.

\section{References}

1. Talley NJ. Definitions, epidemiology, and impact of chronic constipation. Rev Gastroenterol Disord 2004;4(suppl 2):S3-S10.

2. Longstreth GF, Thompson WG, Chey WD, Houghton LA, Mearin F, Spiller RC. Functional bowel disorders. Gastroenterology 2006; 130:1480-1491.

3. Pare P, Ferrazzi S, Thompson WG, Irvine EJ, Rance L. An epidemiological survey of constipation in canada: definitions, rates, demographics, and predictors of health care seeking. Am J Gastroenterol 2001;96:3130-3137.

4. Johanson JF, Kralstein J. Chronic constipation: a survey of the patient perspective. Aliment Pharmacol Ther 2007;25:599-608.

5. Wald A. Diagnosis of constipation in primary and secondary care. Rev Gastroenterol Disord 2004;4(suppl 2):S28-S33.

6. Walter S, Hallböök O, Gotthard R, Bergmark M, Sjödahl R. A population-based study on bowel habits in a Swedish community: prevalence of faecal incontinence and constipation. Scand J Gastroenterol 2002;37:911-916.

7. Sandler RS, Drossman DA. Bowel habits in young adults not seeking health care. Dig Dis Sci 1987;32:841-845.

8. Harari D, Gurwitz JH, Avorn J, Bohn R, Minaker KL. How do older persons define constipation? Implications for therapeutic management. J Gen Intern Med 1997;12:63-66.

9. Herz MJ, Kahan E, Zalevski S, Aframian R, Kuznitz D, Reichman S. Constipation: a different entity for patients and doctors. Fam Pract 1996;13:156-159.

10. Wolfsen CR, Barker JC, Mitteness LS. Constipation in the daily lives of frail elderly people. Arch Fam Med 1993;2:853-858.

11. Kim HS, Shin DW, Lee WC, Kim YT, Cho B. National screening program for transitional ages in Korea: a new screening for strengthening primary prevention and follow-up care. J Korean Med Sci 2012;27(suppl):S70-S75.

12. Higgins PD, Johanson JF. Epidemiology of constipation in North America: a systematic review. Am J Gastroenterol 2004;99:750-759.

13. Everhart JE, Go VL, Johannes RS, Fitzsimmons SC, Roth HP, White LR. A longitudinal survey of self-reported bowel habits in the United States. Dig Dis Sci 1989;34:1153-1162.

14. Talley NJ, Fleming KC, Evans JM, et al. Constipation in an elderly community: a study of prevalence and potential risk factors. Am J Gastroenterol 1996;91:19-25.

15. McCrea GL, Miaskowski C, Stotts NA, Macera L, Paul SM, Varma MG. Gender differences in self-reported constipation characteristics, symptoms, and bowel and dietary habits among patients attending a specialty clinic for constipation. Gend Med 2009;6:259271.

16. Talley NJ, Weaver AL, Zinsmeister AR, Melton LJ 3rd. Functional constipation and outlet delay: a population-based study. Gastroenterology 1993;105:781-790.

17. Choung RS, Locke GR 3rd, Schleck CD, Zinsmeister AR, Talley NJ. Cumulative incidence of chronic constipation: a populationbased study 1988-2003. Aliment Pharmacol Ther 2007;26:1521- 
1528

18. Gwee KA, Ghoshal UC, Gonlachanvit S, et al. Primary care management of chronic constipation in Asia: the ANMA chronic constipation tool. J Neurogastroenterol Motil 2013;19:149-160.
19. American College of Gastroenterology Chronic Constipation Task Force. An evidence-based approach to the management of chronic constipation in North America. Am J Gastroenterol 2005;100(suppl 1):S1-S4. 